\title{
Enhanced catalytic activity without the use of an external light source using microwave-synthesized $\mathrm{CuO}$ nanopetals
}

\author{
Govinda Lakhotiya ${ }^{* 1,2}$, Sonal Bajaj ${ }^{2}$, Arpan Kumar Nayak ${ }^{1}$, Debabrata Pradhan ${ }^{1}$, \\ Pradip Tekade ${ }^{2}$ and Abhimanyu Rana*3
}

\author{
Full Research Paper \\ Address: \\ ${ }^{1}$ Material Science Center, Indian Institute of Technology Kharagpur, \\ Kharagpur-721302, W.B., India, ${ }^{2}$ Jankidevi Bajaj College of Science, \\ Wardha-442001, M.S., India and ${ }^{3} \mathrm{MESA}+$ Institute for \\ Nanotechnology, University of Twente, 7500 AE, Enschede, \\ Netherlands \\ Email: \\ Govinda Lakhotiya* - lakhotiya.govinda@gmail.com; \\ Abhimanyu Rana* - rana.abhimanyu@gmail.com \\ ${ }^{*}$ Corresponding author \\ Keywords: \\ $\mathrm{CuO}$ nanopetals; dark catalytic activity; fast degradation of dyes; \\ microwave synthesis
}

\author{
Beilstein J. Nanotechnol. 2017, 8, 1167-1173. \\ doi:10.3762/bjnano.8.118 \\ Received: 06 February 2017 \\ Accepted: 25 April 2017 \\ Published: 30 May 2017 \\ Associate Editor: R. Xu \\ (C) 2017 Lakhotiya et al.; licensee Beilstein-Institut. \\ License and terms: see end of document.
}

\begin{abstract}
We report enhanced catalytic activity of $\mathrm{CuO}$ nanopetals synthesized by microwave-assisted wet chemical synthesis. The catalytic reaction of $\mathrm{CuO}$ nanopetals and $\mathrm{H}_{2} \mathrm{O}_{2}$ was studied with the application of external light source and also under dark conditions for the degradation of the hazardous dye methylene blue. The $\mathrm{CuO}$ nanopetals showed significant catalytic activity for the fast degradation of methylene blue and rhodamine $\mathrm{B}(\mathrm{RhB})$ under dark conditions, without the application of an external light source. This increased catalytic activity was attributed to the co-operative role of $\mathrm{H}_{2} \mathrm{O}_{2}$ and the large specific surface area $\left(\approx 40 \mathrm{~m}^{2} \cdot \mathrm{g}^{-1}\right)$ of the nanopetals. We propose a detail mechanism for this fast degradation. A separate study of the effect of different $\mathrm{H}_{2} \mathrm{O}_{2}$ concentrations for the degradation of methylene blue under dark conditions is also illustrated.
\end{abstract}

\section{Introduction}

Controlling air quality and water pollutants is a big challenge for environmental research [1]. Particularly, efforts have been taken to control these pollutants with the development of cost effective and ecologically friendly methods [2]. Metal oxides have attracted significant attention as a photocatalyst for the degradation of these pollutants [3-6]. Copper oxide $(\mathrm{CuO})$ is one of the most efficient materials for the oxidation of the air pollutant carbon monoxide ( $\mathrm{CO}$ ) [7-9]. $\mathrm{CuO}$ is one of the few p-type metal oxide semiconductors with a narrow band gap $\approx 1.24 \mathrm{eV}[10]$. The properties of $\mathrm{CuO}$ nanomaterials (nanoparticles, nanowires, nanosheets, etc.) are closely related to morphology and crystallite size [7]. These different nanoscale morphologies enhance the photoconductive and photochemical properties in various energy applications [7]. Being inexpensive, nontoxic, and readily available, $\mathrm{CuO}$ has attracted particular attention. However, in the degradation of water pollutants 
(e.g., industrial dyes) as a photocatalytic oxidative species, $\mathrm{CuO}$ is found to be less effective as compared to other metal oxides [8-12]. Thus, in order to enhance its photocatalytic activity, $\mathrm{CuO}$ can be used with hydrogen peroxide $\left(\mathrm{H}_{2} \mathrm{O}_{2}\right)$ [12-21] However, the degradation time of dyes is an important problem when using $\mathrm{CuO}$ as the photocatalyst.

Here, we have adopted the simple microwave-assisted route for the wet chemical surfactantless synthesis of copper oxide $(\mathrm{CuO})$ nanostructures (nanoflowers and nanopetals) having a large specific surface area. The catalytic reaction of $\mathrm{CuO}$ nanopetals and $\mathrm{H}_{2} \mathrm{O}_{2}$ was studied under the application of an external light source and also under dark conditions for the degradation of hazardous dyes such as methylene blue and rhodamine $\mathrm{B}$. We report enhanced catalytic activity of the synthesized $\mathrm{CuO}$ nanopetals, even without the use of an external light source (UV/ visible light) for the degradation of these dyes. This is attributed to the role of $\mathrm{H}_{2} \mathrm{O}_{2}$ and the large specific surface area of the nanopetals. The amount of the catalyst ( $\mathrm{CuO}$ nanopetals) and the hazardous $\mathrm{H}_{2} \mathrm{O}_{2}$ is minimized, and the reproducibility of the degradation of the dye with the same catalyst has been tested. The catalytic activity of $\mathrm{CuO}$ nanopetals activated by irradiation with photons (visible light) in the absence of $\mathrm{H}_{2} \mathrm{O}_{2}$ is also studied and compared with the activity under dark conditions.

\section{Results and Discussion}

\section{Structural and morphological study}

Figure 1a illustrates X-ray diffraction (XRD) patterns of $\mathrm{CuO}$ nanomaterials synthesized by varying the reaction duration of 5 , 10 , and $15 \mathrm{~min}$. The sample obtained after $5 \mathrm{~min}$ of reaction time shows the diffraction peaks of both $\mathrm{CuO}$ and $\mathrm{Cu}_{2} \mathrm{O}$ (marked by $*$ ), indicating mixed-phase growth. It is interesting to observe that with the increase in the reaction duration, the diffraction peaks for $\mathrm{Cu}_{2} \mathrm{O}$ disappear. For the samples obtained after 10 and 15 min of reaction time, the XRD pattern matches with JCPDS card no. 01-080-1916, which confirms the formation of phase-pure monoclinic $\mathrm{CuO}$. The average crystallite size for the samples obtained after 10 and $15 \mathrm{~min}$ was calculated by using the Scherrer equation and is estimated to be $\approx 11 \mathrm{~nm}$. As the sample obtained after 5 min exhibits phase impurity, only samples obtained with the reaction duration of 10 and $15 \mathrm{~min}$ were considered for further characterization.

Figure 1b,c shows field-emission scanning electron microscope (FESEM) images of $\mathrm{CuO}$ nanostructures synthesized with microwave irradiation for $10 \mathrm{~min}$ and $15 \mathrm{~min}$. The $\mathrm{CuO}$ sample obtained with the reaction time of $10 \mathrm{~min}$ was found to resemble a flower-like morphology. Increasing the reaction duration to 15 min resulted in distinct and individual, uniform features having a petal-like morphology, which is clearly visible
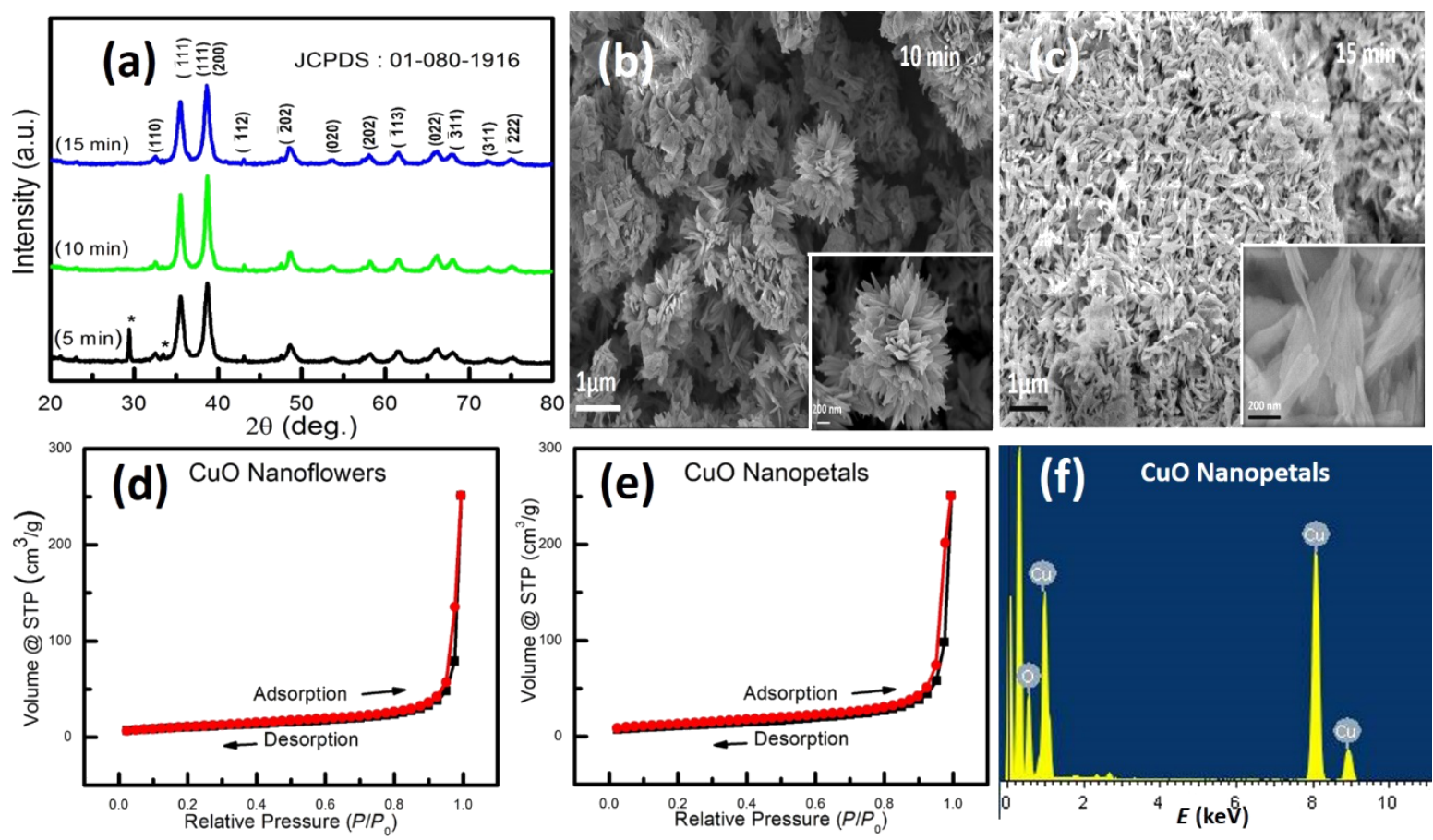

Figure 1: (a) XRD patterns of $\mathrm{CuO}$ nanomaterials synthesized by varying the reaction duration of $5 \mathrm{~min}, 10 \mathrm{~min}$, and $15 \mathrm{~min}$. FESEM images of CuO nanostructures obtained for the synthesis duration of (b) $10 \mathrm{~min}$ and (c) $15 \mathrm{~min}$. The scale bar for the insets in (b, c) is $200 \mathrm{~nm}$. Nitrogen adsorption-desorption isotherm for (d) CuO nanoflowers and (e) CuO nanopetals measured at $77 \mathrm{~K}$. (f) EDAX spectra of CuO nanopetals. 
in Figure 1c. The average width and length of these petal-like features are measured to be 250 and $400 \mathrm{~nm}$, respectively. The insets of Figure 1b,c show the corresponding, magnified image, illustrating their size and morphology. The prolonged microwave agitation is believed to provide the necessary thermal energy for the morphological transformation. This can be inferred on the basis of the similarity in the morphological parameters of both the nanostructures. The growth of these surfactant-free nanostructures depends on certain parameters, including the concentration of $\mathrm{NaOH}$, which promotes the preferential growth of $\mathrm{CuO}$ primary crystals along the $<010>$ and suppresses the growth in $<001>[22,23]$. This preferential growth of the $\mathrm{CuO}$ nanostructure has also been observed in the sample obtained after a reaction time of $5 \mathrm{~min}$, where some flake-like morphology is formed (Supporting Information File 1, Figure S1).

\section{Surface study}

The Brunauer-Emmett-Teller (BET) technique was used to measure the surface area, pore radius, and pore volume of the $\mathrm{CuO}$ nanoflowers and nanopetals obtained by microwave synthesis at a duration of 10 and $15 \mathrm{~min}$, respectively. Figure $1 \mathrm{~d}$,e shows nitrogen adsorption-desorption plots for the $\mathrm{CuO}$ nanoflowers and nanopetals. The effective specific surface area, pore radius and pore volume of nanoflowers (and nanopetals) were measured to be $37.2 \mathrm{~m}^{2} \cdot \mathrm{g}^{-1}\left(39.87 \mathrm{~m}^{2} \cdot \mathrm{g}^{-1}\right), 17.48 \AA$ $(17.646 \AA)$, and $0.38 \mathrm{~mL} \cdot \mathrm{g}^{-1}\left(0.38 \mathrm{~mL} \cdot \mathrm{g}^{-1}\right)$, respectively. The marginal increase in the surface area of nanopetals as compared to nanoflowers supports the hypothesis of disintegration of nanoflowers into nanopetals with increasing reaction duration. It should be noted that the specific surface area of the products in the present work is larger than that of previous reports on materials with similar morphology [24]. Figure 1f depicts the energy disperse X-ray photon spectroscopy (EDS) spectra of nanopetals of $\mathrm{CuO}$, which confirms the stoichiometry and atomic percent of the synthesized material. The effective specific surface area of the sample obtained after a reaction duration of $\approx 5 \mathrm{~min}$ was found to be $\approx 25.58 \mathrm{~m}^{2} \cdot \mathrm{g}^{-1}$ (Supporting Information File 1, Figure S2), which is in good agreement with the preferential growth of nanocrystals along a certain direction with respect to time. As the effective surface area of as-synthesized nanopetals was larger than that of as-synthesized nanoflowers with the same morphology, further experiments were performed with as-synthesized nanopetals.

\section{Optical study}

The UV-vis absorption spectra of as-synthesized $\mathrm{CuO}$ nanopetals is shown in the Figure 2a. It reflects a wide absorption spectrum up to $700 \mathrm{~nm}$ covering almost the entire visible spectrum. The absorption onset was estimated from the Tauc's plot as shown in Figure $2 \mathrm{~b}$. The band gap of $\mathrm{CuO}$ nanopetals was calculated by extrapolating the linear part of the plot of $(\alpha h v)^{1 / 2}$ vs $h v$ and is found to be $\approx 1.85 \mathrm{eV}$ as shown in Figure $2 \mathrm{~b}$. This is different from the bulk bandgap of $\mathrm{CuO}$, which is $1.24 \mathrm{eV}[10]$. This blue shift in the absorption further confirms the nanometer range of synthesized material.
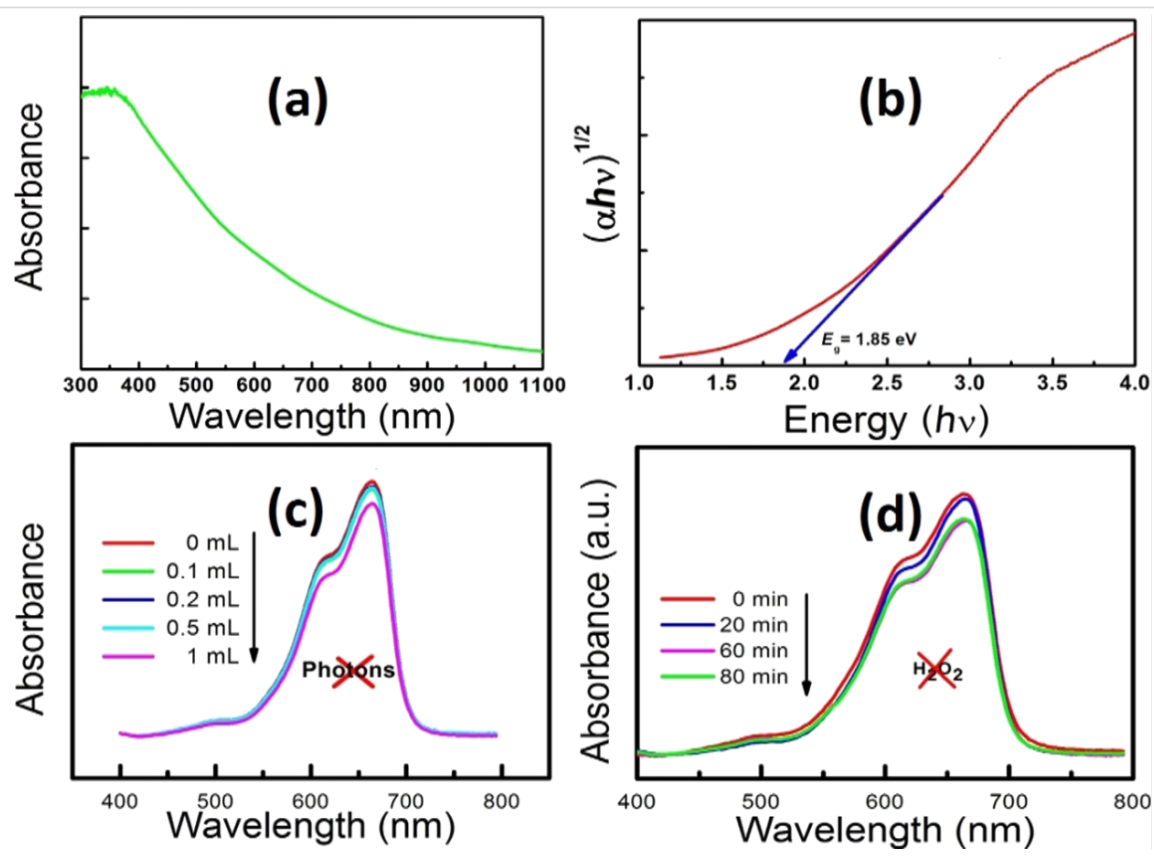

Figure 2: (a) UV-vis absorption spectra of CuO nanopetals. (b) Tauc's plot for CuO nanopetals (c) UV-vis absorption spectra illustrating the effect of different concentrations of $\mathrm{H}_{2} \mathrm{O}_{2}$ in methylene blue degradation in the absence of $\mathrm{CuO}$ nanopetals (catalyst) under dark conditions. (d) UV-vis absorption spectrum of methylene blue degradation using $\mathrm{CuO}$ nanopetals as a photocatalyst for different durations. 


\section{Catalytic activity of nanopetals for the degradation of methylene blue}

The use of inorganic semiconductors as a heterogeneous, photocatalytic material has been extensively investigated under UV-vis light illumination, yet continues to attract even more attention due to the use of advanced materials in the process [3-5]. The catalytic photo-degradation of dyes takes place with the excitation of a catalyst using UV-vis light, leading to the generation of electrons and holes which are further responsible for the degradation through the formation of radicals $[6,25]$ The wide band gap, high surface area of $\mathrm{CuO}$ nanopetals was expected to be suitable for the photocatalytic activity for the degradation of the common cationic dye methylene blue (MB), and hence initially, a study has been carried out in which $40 \mathrm{mg}$ of $\mathrm{CuO}$ nanopetal powder was dispersed in $40 \mathrm{~mL}$ of $50 \mu \mathrm{M}$ MB solution. This solution was allowed to stir for $\approx 30 \mathrm{~min}$ under dark conditions and was then subjected to irradiation using an incandescent lamp (Philips, $200 \mathrm{~W}$ ) at a working distance of $100 \mathrm{~cm}$. Aliquots of about $4 \mathrm{~mL}$ were taken from the suspension at regular intervals and were centrifuged to filter suspended $\mathrm{CuO}$ powder. The MB concentration in the filtered suspension was studied with a Perkin Elmer Lambda 750 $\mathrm{UV}-\mathrm{vis}$ spectrophotometer. Figure $2 \mathrm{~b}$ shows the UV-vis absorption spectra of the aliquots taken out at different time intervals. In this study, the MB degradation rate is found to be very slow and only $\approx 10 \%$ degradation has been observed in three hours. No further noticeable bleaching was observed within the next hour. This slow rate of degradation is in agreement with Miyauchi et al. [13], which may be due to the more negative valence band position of $\mathrm{CuO}$ than that of the redox potential required for producing free radicals for effective degradation. This slow rate of degradation was then overcome by introducing $\mathrm{H}_{2} \mathrm{O}_{2}$ along with $\mathrm{CuO}$, which resulted in the enhancement of the degradation of pollutants $[12,26]$. Recently, Zhang et al. successfully enhanced the catalytic activity by using peroxymonosulfate in their system instead of $\mathrm{H}_{2} \mathrm{O}_{2}$ [6]. Few reports are available in which degradation of water pollutants were studied with $\mathrm{CuO}$ and $\mathrm{H}_{2} \mathrm{O}_{2}$ without photon irradiation (UV/visible) [27,28]. Therefore, a separate study was carried out to investigate the effect of different concentrations of $\mathrm{H}_{2} \mathrm{O}_{2}$ for $\mathrm{MB}$ degradation in the absence of $\mathrm{CuO}$ nanopetals (catalyst) without any irradiation (UV/visible light). Figure 2c shows the UV-vis absorption spectra for different concentrations of $\mathrm{H}_{2} \mathrm{O}_{2}$ in $\mathrm{MB}$ solution, without catalyst, after one hour without photon irradiation. As can be seen from the Figure 2c, the concentration of $\mathrm{H}_{2} \mathrm{O}_{2}$ with less than $1 \mathrm{~mL}$ had almost no effect on the degradation of the dye. However, the higher concentration of $\mathrm{H}_{2} \mathrm{O}_{2}$ alone was found to be effective to some extent in the degradation of dye $(6 \%$ in $1 \mathrm{~h})$ even in the absence of catalyst. Furthermore, an experiment was performed by adding $1 \mathrm{~mL}$ of $\mathrm{H}_{2} \mathrm{O}_{2}$ to a solution containing $40 \mathrm{mg} \mathrm{CuO}$ nanopetals in $40 \mathrm{~mL}$ of $50 \mu \mathrm{M} \mathrm{MB}$ solution. The solution went from a bluish color (MB solution) to colorless within two minutes. This fast activity without any irradiation unveils the interesting co-operative role of $\mathrm{CuO}$ and $\mathrm{H}_{2} \mathrm{O}_{2}$ for the degradation of MB.

Further experiments were focused to achieve a higher rate of MB degradation with the optimum use of the cost effective catalyst and the hazardous $\mathrm{H}_{2} \mathrm{O}_{2}$. The amount of $\mathrm{CuO}$ nanopetals was minimized and fixed at $10 \mathrm{mg}$ and concentrations of $\mathrm{H}_{2} \mathrm{O}_{2}$ were varied $(0.1 \mathrm{~mL}, 0.2 \mathrm{~mL}$ and $0.5 \mathrm{~mL})$ to study the catalytic activity for the degradation of $40 \mathrm{~mL}$ of $50 \mu \mathrm{M} \mathrm{MB}$ solution without irradiation. Figure $3 \mathrm{a}-\mathrm{c}$ depicts the UV-vis absorption spectra of MB aliquot using $0.1 \mathrm{~mL}, 0.2 \mathrm{~mL}$ and $0.5 \mathrm{~mL}$ of $\mathrm{H}_{2} \mathrm{O}_{2}$, respectively, with $10 \mathrm{mg}$ of catalyst. It can be clearly observed that the concentration of $\mathrm{H}_{2} \mathrm{O}_{2}$ has an obvious effect on the degradation time, which decreases with increasing $\mathrm{H}_{2} \mathrm{O}_{2}$ concentration.

As can be seen from Figure 3c, the complete degradation of the dye within 30 min was successfully achieved with $0.5 \mathrm{~mL} \mathrm{H}_{2} \mathrm{O}_{2}$ along with $10 \mathrm{mg} \mathrm{CuO}$ nanopetals. Figure $3 \mathrm{~d}$ represents the kinetics of the $\mathrm{MB}$ degradation with $0.5 \mathrm{~mL} \mathrm{H}_{2} \mathrm{O}_{2}$ and $10 \mathrm{mg}$ $\mathrm{CuO}$ nanopetals. The apparent rate constant of this degradation was calculated from the slope of $\ln \left(C / C_{0}\right)$ vs time (Figure $3 \mathrm{e}$ ) and found to be $0.087 \mathrm{~min}^{-1}$. In order to examine the stability of the catalyst used for MB degradation, experiments with $0.5 \mathrm{~mL} \mathrm{H} \mathrm{H}_{2} \mathrm{O}_{2}$ and $10 \mathrm{mg}$ nanopetals were repeated five times using the same $\mathrm{CuO}$ nanopetals without irradiation. Figure $3 \mathrm{f}$ shows the efficiency of the catalyst (five continuous cycles) in which degradation was efficiently achieved within $30 \mathrm{~min}$. In the fifth cycle, the same catalyst could still successfully degrade $\approx 94 \%$ of MB dye in $30 \mathrm{~min}$. This highlights the efficacy and high stability of $\mathrm{CuO}$ nanopetals as a catalyst in this dye degradation activity. The phase and morphology of $\mathrm{CuO}$ nanopetals after the fifth cycle was also confirmed by XRD and FESEM (not shown).

The catalytic activity of the sample obtained after $10 \mathrm{~min}$ (nanoflowers), whose surface area was closer to nanopetals, was also checked in the presence of $\mathrm{H}_{2} \mathrm{O}_{2}$ under dark conditions. For this, $10 \mathrm{mg}$ of $\mathrm{CuO}$ nanoflowers along with $0.5 \mathrm{~mL}$ of $\mathrm{H}_{2} \mathrm{O}_{2}$ was used in a $40 \mathrm{~mL}, 50 \mu \mathrm{M}$ solution of $\mathrm{MB}$. As expected, the nanoflowers could efficiently degrade $\approx 93 \%$ of MB in $30 \mathrm{~min}$ (Supporting Information File 1, Figure S3).

\section{Reaction mechanism}

It is well understood that the rate of degradation of organic dyes depends on the formation of free radicals $[7,25,28]$. The fast degradation of $\mathrm{MB}$ with the assistance of $\mathrm{H}_{2} \mathrm{O}_{2}$ and as-synthesized $\mathrm{CuO}$ nanostructures (petals/flowers) without irradiation 

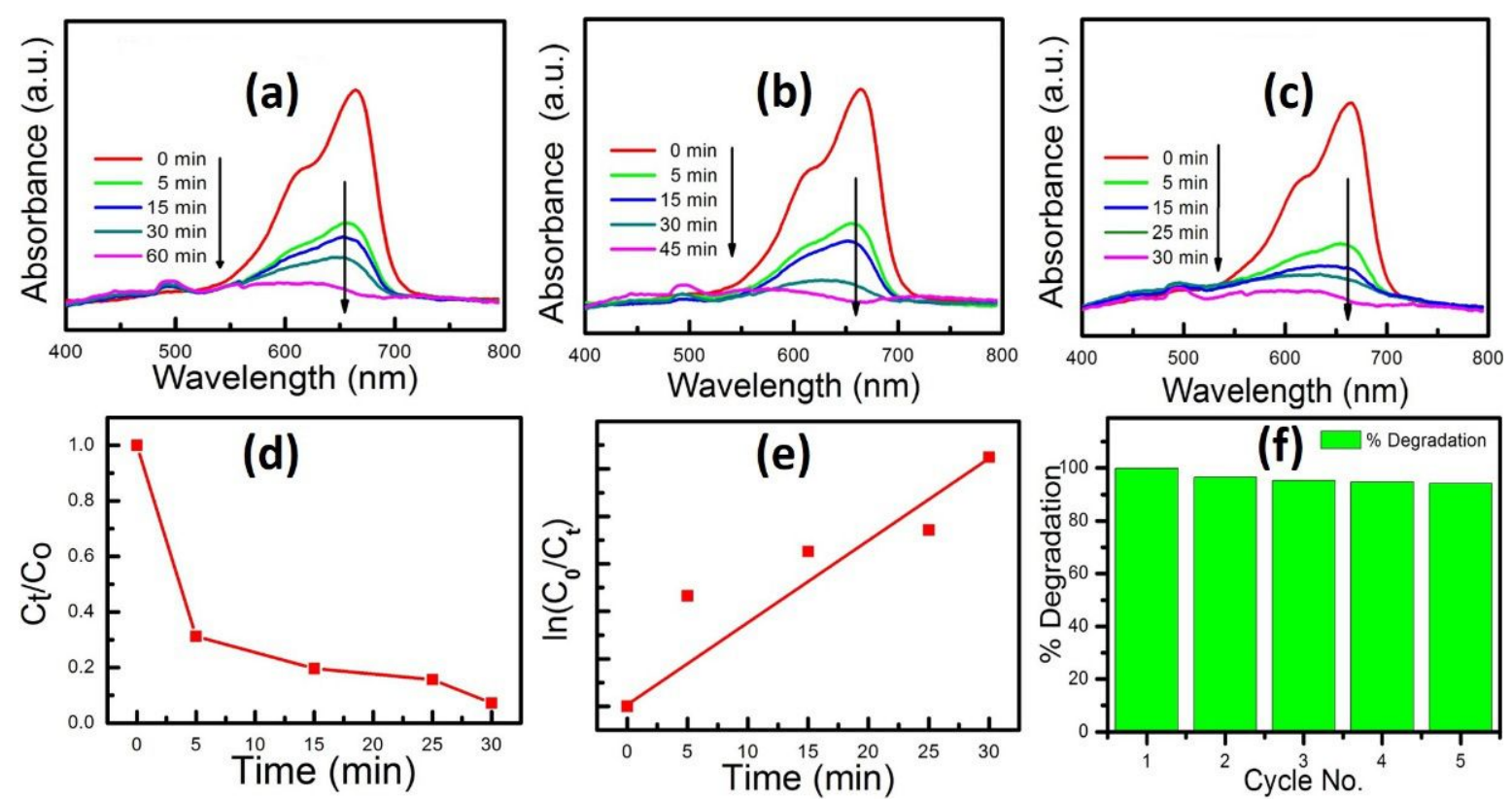

Figure 3: (a) UV-vis absorption spectra for $\mathrm{MB}$ degradation for different duration for $10 \mathrm{mg}$ nanopetals of $\mathrm{CuO}$ and $0.1 \mathrm{~mL} \mathrm{H}_{2} \mathrm{O}_{2}$. (b) UV-vis absorption spectra for MB degradation for different duration for $10 \mathrm{mg}$ nanopetals of $\mathrm{CuO}$ and $0.2 \mathrm{~mL} \mathrm{H}_{2} \mathrm{O}_{2}$. (c) UV-vis absorption spectra for MB degradation for different duration for $10 \mathrm{mg}$ nanopetals of $\mathrm{CuO}$ and $0.5 \mathrm{~mL} \mathrm{H}_{2} \mathrm{O}_{2}$. (d) The $\mathrm{MB}$ degradation rate in the presence of $0.5 \mathrm{~mL} \mathrm{H}_{2} \mathrm{O}_{2}$ and $10 \mathrm{mg}$ $\mathrm{CuO}$ nanopetals. (e) Kinetics of degradation with $0.5 \mathrm{~mL} \mathrm{H} \mathrm{O}_{2}$ and $10 \mathrm{mg} \mathrm{CuO}$ nanopetals. (f) The \% degradation vs cycle number for MB degradation with $0.5 \mathrm{~mL} \mathrm{H} \mathrm{H}_{2}$ and $10 \mathrm{mg} \mathrm{CuO}$ nanopetals.

with photons is believed to be the co-operative phenomenon and proceeds through the following two vital steps:

$$
\begin{gathered}
{[\mathrm{Cu}(\mathrm{II})]+\mathrm{H}_{2} \mathrm{O}_{2} \longrightarrow[\mathrm{Cu}(\mathrm{II})] \cdots \mathrm{H}_{2} \mathrm{O}_{2} \longrightarrow[\mathrm{Cu}(\mathrm{I})]+{ }^{\bullet} \mathrm{O}_{2} \mathrm{H}+\mathrm{H}^{+}} \\
{[\mathrm{Cu}(\mathrm{I})]+\mathrm{H}_{2} \mathrm{O}_{2} \longrightarrow[\mathrm{Cu}(\mathrm{I})] \cdots \mathrm{H}_{2} \mathrm{O}_{2} \longrightarrow[\mathrm{Cu}(\mathrm{II})]+{ }^{\bullet} \mathrm{OH}+{ }^{-} \mathrm{OH}} \\
{ }^{\circ} \mathrm{O}_{2} \mathrm{H}+\mathrm{H}_{2} \mathrm{O}_{2} \longrightarrow \mathrm{H}_{2} \mathrm{O}+{ }^{\bullet} \mathrm{OH}+\mathrm{O}_{2} \\
\cdot \mathrm{OH}+\mathrm{H}_{2} \mathrm{O}_{2} \longrightarrow \mathrm{H}_{2} \mathrm{O}+{ }^{\bullet} \mathrm{O}_{2} \mathrm{H}
\end{gathered}
$$

At first, $\mathrm{H}_{2} \mathrm{O}_{2}$ reacts with the complex surface of nanopetals $[\mathrm{Cu}(\mathrm{II})]$ and reduces it to produce free radical ${ }^{\circ} \mathrm{O}_{2} \mathrm{H}$ and species $[\mathrm{Cu}(\mathrm{I})]$, which again, upon reaction with $\mathrm{H}_{2} \mathrm{O}_{2}$, become oxidized to give back $[\mathrm{Cu}(\mathrm{II})]$ along with radical ${ }^{\circ} \mathrm{OH}$, as represented in Equation 1. Thus, the free radicals ${ }^{\circ} \mathrm{OH}$ and ${ }^{\circ} \mathrm{O}_{2} \mathrm{H}$ are generated in the reaction solution due to the oxidizing and reducing property of $\mathrm{H}_{2} \mathrm{O}_{2}$. These free radicals may be adsorbed on $\mathrm{H}_{2} \mathrm{O}_{2}$ and can produce each other as depicted in Equation 2. Then, these free radicals ${ }^{\circ} \mathrm{OH}$ and ${ }^{\circ} \mathrm{O}_{2} \mathrm{H}$, which have a very high oxidizing capability, interact with the $\mathrm{S}$ atom in the middle heterogeneous ring of MB dye. This leads to the very easy degradation of the dye and produces $\mathrm{SO}_{4}{ }^{2-}$ ions (the main product of MB oxidation) [29]. The formation of $\mathrm{SO}_{4}{ }^{2-}$ ions in the mineralized degraded product was confirmed by adding $\mathrm{BaCl}_{2}$ to it, which produces the white color precipitate of
$\mathrm{BaSO}_{4}$. Here, the larger surface area of $\mathrm{CuO}$ nanopetals provides higher adsorption of $\mathrm{H}_{2} \mathrm{O}_{2}$ molecules for more radical formation to enhance the rate of degradation. Thus, the complete degradation reaction of $\mathrm{MB}$ under dark conditions was achieved in ample time and found to proceed through the co-operative activity between $\mathrm{CuO}$ nanostructures and $\mathrm{H}_{2} \mathrm{O}_{2}$.

\section{Catalytic activity of nanopetals for the degradation of rhodamine $B$}

The catalytic performance of synthesized $\mathrm{CuO}$ nanopetals was also extended for the degradation of rhodamine $\mathrm{B}(\mathrm{RhB})$ using $40 \mathrm{~mL}$ of a $50 \mu \mathrm{M}$ solution of $\mathrm{RhB}$ with the same experimental conditions, i.e., $10 \mathrm{mg}$ catalyst and $0.5 \mathrm{~mL} \mathrm{H}_{2} \mathrm{O}_{2}$ and was found to be efficient (Supporting Information File 1, Figure S4).This confirms that the same as-synthesized $\mathrm{CuO}$ nanopetals can also be optimized for the efficient degradation of hazardous dyes other than MB.

\section{Conclusion}

In summary, we have synthesized $\mathrm{CuO}$ nanoflowers and nanopetals in the absence of any surfactant and/or template using a microwave-assisted wet chemical technique. These nanostructures exhibited an increased band gap with larger surface area. The $\mathrm{CuO}$ nanopetals, with a specific surface area $\approx 40 \mathrm{~m}^{2} \cdot \mathrm{g}^{-1}$, have proven to be an efficient catalyst for the degradation of water pollutant, industrial dyes, even in the absence 
of photon irradiation (UV/visible). A corresponding mechanism for the fast degradation observes was also proposed.

\section{Experimental \\ Materials and instrumentation}

Commercial, high-grade copper sulphate $\left(\mathrm{CuSO}_{4} \cdot 5 \mathrm{H}_{2} \mathrm{O}\right.$, $99.95 \%)$, sodium hydroxide $(\mathrm{NaOH})$, ethanol $\left(\mathrm{C}_{2} \mathrm{H}_{5} \mathrm{OH}\right)$, acetone $\left(\mathrm{C}_{3} \mathrm{H}_{6} \mathrm{O}\right)$, methylene blue $(\mathrm{MB})$, hydrogen peroxide $\left(\mathrm{H}_{2} \mathrm{O}_{2}\right.$, $30 \%)$, and rhodamine $\mathrm{B}(\mathrm{RhB})$ were obtained from Sigma-Aldrich, Merck and SD Fine. $\mathrm{CuO}$ nanostructures were characterized by X-ray diffraction by a PANalytical high-resolution X-ray diffractometer (PW 3040/60) operated at $40 \mathrm{kV}$ and $30 \mathrm{~mA}$ using $\mathrm{Cu} \mathrm{K} \alpha \mathrm{X}$-rays (1.54 $\AA$ ), energy dispersive $\mathrm{X}$-ray spectroscopy using Oxford detectors, field-emission scanning electron microscopy using a Carl Zeiss SUPRA 40 instrument, and the surface area was characterized using a Quantachrome ChemBET TPR/TPD analyzer. The optical properties were analyzed using a UV-vis absorption spectrophotometer by Schimadzu 1800 .

\section{Material synthesis}

In the present study, the microwave-assisted synthesis of $\mathrm{CuO}$ nanoflowers and nanopetals was carried out using a microwaveirradiated wet chemical technique. At first, equimolar solutions $(0.5 \mathrm{M})$ of copper sulphate and sodium hydroxide were prepared separately in $25 \mathrm{~mL}$ of ethanol and were allowed to stir at room temperature for about $15 \mathrm{~min}$. Thereafter, sodium hydroxide solution was added drop wise to copper sulphate solution. The resulting mixture was transferred to the microwave chamber with the reaction conditions of $700 \mathrm{~W}$ for $10 \mathrm{~min}$ or 15 min. During the reaction, the color of the solution changed initially from blue to colorless and then slowly turned black. The black colloidal solution was centrifuged to separate out the precipitates. These precipitates were then washed using double distilled water, absolute ethanol, and acetone in sequence. This procedure was repeated several times. Finally, the black powder was dried at $60{ }^{\circ} \mathrm{C}$ for $4 \mathrm{~h}$ and used for further characterization. The synthesis parameters such as reaction time, molar concentration of the precursors, and power of microwave irradiation were monitored so as to obtain phase-pure $\mathrm{CuO}$ nanoflowers and nanopetals. All the reactions were carried out using Raga's commercial scientific microwave oven attached with a reflux system.

\section{Catalytic activity study}

The photocatalytic and the catalytic activity under dark conditions of the as-synthesized $\mathrm{CuO}$ nanopetals were studied for the degradation of a common cationic dye, methylene blue (MB), in the absence and presence of $\mathrm{H}_{2} \mathrm{O}_{2}$, respectively. For the photocatalytic activity study, $40 \mathrm{mg}$ of $\mathrm{CuO}$ nanopetal powder was dispersed in $40 \mathrm{~mL}$ of a $50 \mu \mathrm{M}$ MB solution and allowed to stir for $\approx 30$ min under dark conditions and was then subjected to irradiation using an incandescent lamp (Philips, $200 \mathrm{~W}$ ) at a working distance of $100 \mathrm{~cm}$. The dark catalytic study was performed with $10 \mathrm{mg}$ of $\mathrm{CuO}$ nanopetals and varying concentrations of $\mathrm{H}_{2} \mathrm{O}_{2}$. During both the studies, i.e., under dark conditions and the photocatalytic study, aliquots of about $4 \mathrm{~mL}$ were taken out from the suspension at regular intervals and were centrifuged to filter suspended $\mathrm{CuO}$ powder. The $\mathrm{MB}$ concentration in the filtered suspension was studied with a Perkin Elmer Lambda 750 UV-vis spectrophotometer. The dark catalytic activity of the as-synthesized $\mathrm{CuO}$ nanopetals was also checked for the degradation of RhB under the same experimental conditions.

\section{Supporting Information}

\section{Supporting Information File 1}

Additional figures.

[http://www.beilstein-journals.org/bjnano/content/

supplementary/2190-4286-8-118-S1.pdf]

\section{Acknowledgements}

GL thanks Head, Material Science Center, Indian Institute of Technology, Kharagpur, India and Principal, Jankidevi Bajaj College of Science, Wardha (M.S.), India for providing facilities for carrying out a part of this work. DP acknowledges funding from SERB, DST through the grant SB/S1/IC-15/2013. All the authors agreed on the results and have given approval of the manuscript.

\section{References}

1. Gogate, P. R.; Pandit, A. B. Adv. Environ. Res. (Oxford, U. K.) 2004, 8, 501-551. doi:10.1016/s1093-0191(03)00032-7

2. Rauf, M. A.; Ashraf, S. S. Chem. Eng. J. 2009, 151, 10-18. doi:10.1016/j.cej.2009.02.026

3. Zhao, Q.; Ju, D.; Deng, X.; Huang, J.; Cao, B.; Xu, X. Sci. Rep. 2015, 5, 7874. doi:10.1038/srep07874

4. Shao, M.; Xu, X.; Huang, J.; Zhang, Q.; Ma, L. Sci. Adv. Mater. 2013, 5, 962-981. doi:10.1166/sam.2013.1545

5. Zhao, Q.; Ju, D.; Song, X.; Deng, X.; Ding, M.; Xu, X.; Zeng, H. Sens. Actuators, B 2016, 229, 627-634. doi:10.1016/j.snb.2016.01.129

6. Zhang, S.; Fan, Q.; Gao, H.; Huang, Y.; Liu, X.; Li, J.; Xu, X.; Wang, X. J. Mater. Chem. A 2016, 4, 1414-1422. doi:10.1039/c5ta08400h

7. Zhang, Q.; Zhang, K.; Xu, D.; Yang, G.; Huang, H.; Nie, F.; Liu, C.; Yang, S. Prog. Mater. Sci. 2014, 60, 208-33737. doi:10.1016/j.pmatsci.2013.09.003

8. Lam, S.-M.; Sin, J.-C.; Abdullah, A. Z.; Mohamed, A. R. Desalin. Water Treat. 2012, 41, 131-169. doi:10.1080/19443994.2012.664698

9. Xu, H.; Zhu, G.; Zheng, D.; Xi, C.; Xu, X.; Shen, X. J. Colloid Interface Sci. 2012, 383, 75-81. doi:10.1016/j.jcis.2012.06.017 
10. Chong, M. N.; Jin, B.; Chow, C. W. K.; Saint, C. Water Res. 2010, 44, 2997-3027. doi:10.1016/j.watres.2010.02.039

11. Liu, J.; Jin, J.; Deng, Z.; Huang, S.-Z.; Hu, Z.-Y.; Wang, L.; Wang, C.; Chen, L.-H.; Li, Y.; Van Tendeloo, G.; Su, B.-L. J. Colloid Interface Sci. 2012, 384, 1-9. doi:10.1016/j.jcis.2012.06.044

12. Yang, C.; Su, X.; Xiao, F.; Jian, J.; Wang, J. Sens. Actuators, B 2011, 158, 299-303. doi:10.1016/j.snb.2011.06.024

13. Miyauchi, M.; Nakajima, A.; Watanabe, T.; Hashimoto, K. Chem. Mater. 2002, 14, 2812-2816. doi:10.1021/cm020076p

14. Yu, H.; Yu, J.; Liu, S.; Mann, S. Chem. Mater. 2007, 19, 4327-4334. doi:10.1021/cm070386d

15. Deng, X.; Zhang, Q.; Zhao, Q.; Ma, L.; Ding, M.; Xu, X. Nanoscale Res. Lett. 2015, 10, 8. doi:10.1186/s11671-014-0726-X

16. Deng, X.; Zhang, Q.; Zhou, E.; Ji, C.; Huang, J.; Shao, M.; Ding, M.; Xu, X. J. Alloys Compd. 2015, 649, 1124-1129. doi:10.1016/j.jallcom.2015.07.124

17. Liu, L.; Yang, W.; Li, Q.; Gao, S.; Shang, J. K. ACS Appl. Mater. Interfaces 2014, 6, 5629-5639. doi:10.1021/am500131b

18. Deng, X.; Wang, C.; Zhou, E.; Huang, J.; Shao, M.; Wei, X.; Liu, X.; Ding, M.; Xu, X. Nanoscale Res. Lett. 2016, 11, 29. doi:10.1186/s11671-016-1246-7

19. Wu, F.; Banerjee, S.; Li, H.; Myung, Y.; Banerjee, P. Langmuir 2016, 32, 4485-4493. doi:10.1021/acs.langmuir.6b00915

20. Basnet, P.; Zhao, Y. Catal. Sci. Technol. 2016, 6, 2228-2238. doi:10.1039/C5CY01464F

21. Deng, X.; Wang, C.; Shao, M.; Xu, X.; Huang, J. RSC Adv. 2017, 7, 4329-4338. doi:10.1039/c6ra27634b

22. Jung, A.; Cho, S.; Cho, W. J.; Lee, K.-H. Korean J. Chem. Eng. 2012 29, 243-248. doi:10.1007/s11814-011-0168-4

23. Xu, L.; Xu, H.-Y.; Wang, F.; Zhang, F.-J.; Meng, Z.-D.; Zhao, W.; Oh, W.-C. J. Korean Ceram. Soc. 2012, 49, 151-154. doi:10.4191/kcers.2012.49.2.151

24. Xu, X.; Yang, H.; Liu, Y. CrystEngComm 2012, 14, 5289-5298. doi:10.1039/c2ce25420d

25. Kumar, S. G.; Rao, K. S. R. K. Appl. Surf. Sci. 2017, 391, 124-148. doi:10.1016/j.apsusc.2016.07.081

26. Srivastava, R.; Prathap, M. U. A.; Ore, R. Colloids Surf., A 2011, 392, 271-282. doi:10.1016/j.colsurfa.2011.10.004

27. Zaman, S.; Zainelabdin, A.; Amin, G.; Nur, O.; Willander, M. J. Phys. Chem. Solids 2012, 73, 1320-1325. doi:10.1016/j.jpcs.2012.07.005

28. Gaya, U. I.; Abdullah, A. H. J. Photochem. Photobiol., C: Photochem. Rev. 2008, 9, 1-12. doi:10.1016/j.jphotochemrev.2007.12.003

29. Houas, A.; Lachheb, H.; Ksibi, M.; Elaloui, E.; Guillard, C.; Herrmann, J.-M. Appl. Catal., B 2001, 31, 145-157. doi:10.1016/s0926-3373(00)00276-9

\section{License and Terms}

This is an Open Access article under the terms of the Creative Commons Attribution License

(http://creativecommons.org/licenses/by/4.0), which permits unrestricted use, distribution, and reproduction in any medium, provided the original work is properly cited.

The license is subject to the Beilstein Journal of Nanotechnology terms and conditions: (http://www.beilstein-journals.org/bjnano)

The definitive version of this article is the electronic one which can be found at:

doi:10.3762/bjnano.8.118 